\title{
Subcutaneous phycomycetosis
}

\author{
J. B. LYNCH AND A. D. HUSBAND \\ From the Department of Pathology, University of Khartoum, Sudan
}

SYNOPSIS A case is reported of a subcutaneous mycotic granuloma of the forearm in a young $\vec{\omega}$ Sudanese child. It is thought that, despite the absence of culture studies, the characteristic morphologyo of the fungus and the histological findings permit not only the identification of the causative organism as a phycomycete, but also the realization that it belongs not to the family Mucoracea $\dot{E}$ but to one of the other families of the phycomycetes, viz., Entomophthoraceae or Mortierellaceaei At present the most commonly identified species has been Basidiobolus, of the family Entomoph $\overrightarrow{\mathrm{N}}$ thoraceae. The findings in the present case are closely similar to those reported by Lie Kian Joe and Eng, Njo-Injo Tjoei (1960) in their paper 'Subcutaneous phycomycetosis: a new disease foundP in Indonesia'.

Fungi of the class Phycomycetes, though widely distributed in nature, are only occasionally pathogenic to man. The most important phycomycete, though of doubtful taxonomic position, is Coccidioides immitis, the pathogenic agent of coccidioidomycosis. Another group of phycomycetes of medical importance is the Mucoraceae. Under the title 'mucormycosis' members of three genera belonging to this family, viz., Absidia, Rhizopus, and Mucor, have been most commonly reported. However, these infections are not common, as shown by the reviews of Gregory, Golden, and Haymaker (1943), Baker (1957), and more recently Hutter (1959), who found only 116 cases of mucormycosis in the world literature. Other phycomycetes have been incriminated only rarely as human pathogens but recently there have been several reports of a subcutaneous granuloma caused by organisms of the genus Basidiobolus, in particular Basidiobolus ranarum, of the family Entomophthoraceae, and possibly in one case by an organism of the family Mortierellaceae (Lie Kian Joe, Eng, Njo-Injo Tjoei, Pohan, van der Meulen, and Emmons, 1956; Lie Kian Joe, Eng, Tjokronegoro, and Emmons, 1960; Lie Kia Joe and Eng, 1960).

We present a case of subcutaneous phycomycetosis of similar aetiology occurring in a young Sudanese boy. The diagnosis is based upon the clinical picture, the morphology of the fungus, and the histological features. In the absence of culture studies, which were unfortunately not possible, the exact nature of the causative organism could not be ascertained. However, it is considered, from the close similarity of the clinical and histological findings to those

Received for publication 13 July 1961. reported by the above mentioned authors, that the organism is a phycomycete, probably a member of the family Entomophthoraceae or possibly Mortiereto laceae but not one of the Mucoraceae.

The term 'mucormycosis' is not used in the pre? sent context, for, as pointed out by Bauer, Ajellos Adams, and Useda Hernandez (1955) this term 'is correct only if applied to infections by members of the order Mucoraceae as well as to species of th\& genus Mucor'. In accord therefore with the sug gestion of Lie Kian Joe, Eng, Njo-Injo Tjoe: Tjokronegoro, Schaafma, and Emmons (1959) the more general term 'phycomycetosis' is used here, fop? it includes infections produced by fungi belonging to all three families Mucoraceae, Mortierellacea and Entomophthoraceae.

\section{CASE REPORT}

The patient was a Sudanese boy aged 5 years, who was i뭄 excellent health, but complained of a painless and steadif progressive swelling of the upper part of the right forearri of three months' duration. There was no tenderness ov itching. A history of injury, in particular of a thorf prick, splinter, or insect bite, was not elicited.

Examination showed a firm, diffuse swelling over the upper and outer aspect of the right forearm. It involveg an area approximately $12 \times 9 \mathrm{~cm}$. The affected sub cutaneous tissues were of a uniform cartilaginous cof sistency and were rather sharply demarcated from the neighbouring tissues. The movements of the elbow were slightly limited by the mass of affected tissue but there was no interference with the underlying muscles. Skf sensation over the area was normal; occasional healed cautery marks were present but there were no sinuses. The axillary lymph nodes were not enlarged. He wâs afebrile and there was no clinical evidence of any other 
disease. No laboratory investigations were performed. A provisional diagnosis of a mycosis was made, probably maduromycosis, in view of the frequency of this condition in the Sudan.

At operation all the infected tissue was excised, including the deep fascia and part of the brachioradialis muscle which was involved in the granulomatous process. The area was grafted with split skin grafts taken from the thigh. The wound healed satisfactorily, and three months later there was no evidence of recurrence.

\section{PATHOLOGICAL FINDINGS}

The fixed specimen was an oval mass of tissue approximately $12 \times 9 \times 2 \frac{1}{2} \mathrm{~cm}$. On section the tissue was very firm, avascular, and greyish white. In contrast to the clinical impression, the edges were not well demarcated from the surrounding fibro-fatty connective tissue. Apart from the healed cautery marks the overlying skin appeared normal.

Several blocks of tissue were taken and the sections stained with haematoxylin and eosin. Further special stains were used in the study of the fungus, viz., Gram-Weigert, Mallory's phosphotungstic acid haematoxylin, periodic-acid-Schiff (P.A.S.), Gridley's modification of P.A.S., and Grocott's modification of Gomori's hexamine and silver stain.

\section{HISTOLOGY}

In the rather densely fibrotic granulomatous tissue fairly numerous longitudinal and cross sections of large hyphae are seen, usually singly or in small groups; their diameter varies from $5 \mu$ to $25 \mu$ but occasionally it is greater. Branching is only occasionally observed and definite septae are very rarely identified. The walls of the hyphae are thin but stain prominently in P.A.S. sections. The lumen may be empty, or show a coarse foamy vacuolated appearance with a network of cytoplasmic strands which are strongly P.A.S. positive (Fig. 1). Very occasionally a small nucleus is present (Fig. 2). In sections stained with haematoxylin and eosin the hyphae are most readily identified by a surrounding intensely eosinophilic granular material up to some $25 \mu$ in depth (Fig. 3) but not constantly present; sometimes it surrounds only part of a hypha (Fig. 4). It is only poorly P.A.S. positive, and is not stained in Gram-Weigert preparations but has a reddish colour with Mallory's phosphotungstic acid haematoxylin. Whether or not this eosinophilic material is a secretion of the fungus, a precipitation of a tissue fluid protein, or possibly a result of tissue necrosis has not been ascertained, though we prefer the first explanation.

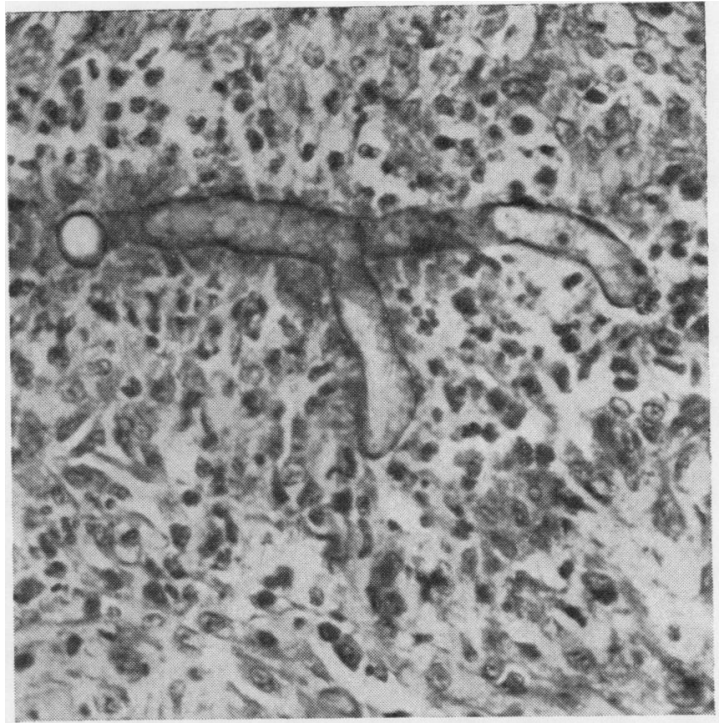

FIG. 1. Branching hypha in an early microabscess (P.A.S. and haematoxylin $\times 280$ ).

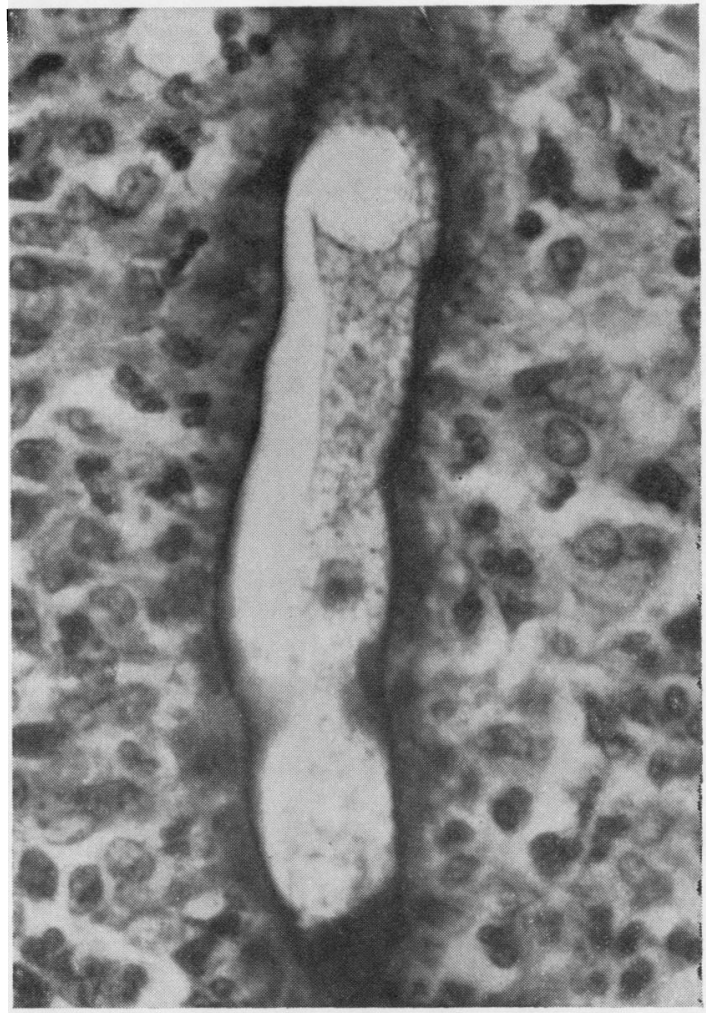

FIG. 2. Hypha showing details of cytoplasm, nucleus, and surrounding eosinophilic substance (P.A.S. and haemato$x y$ lin $\times 750)$. 

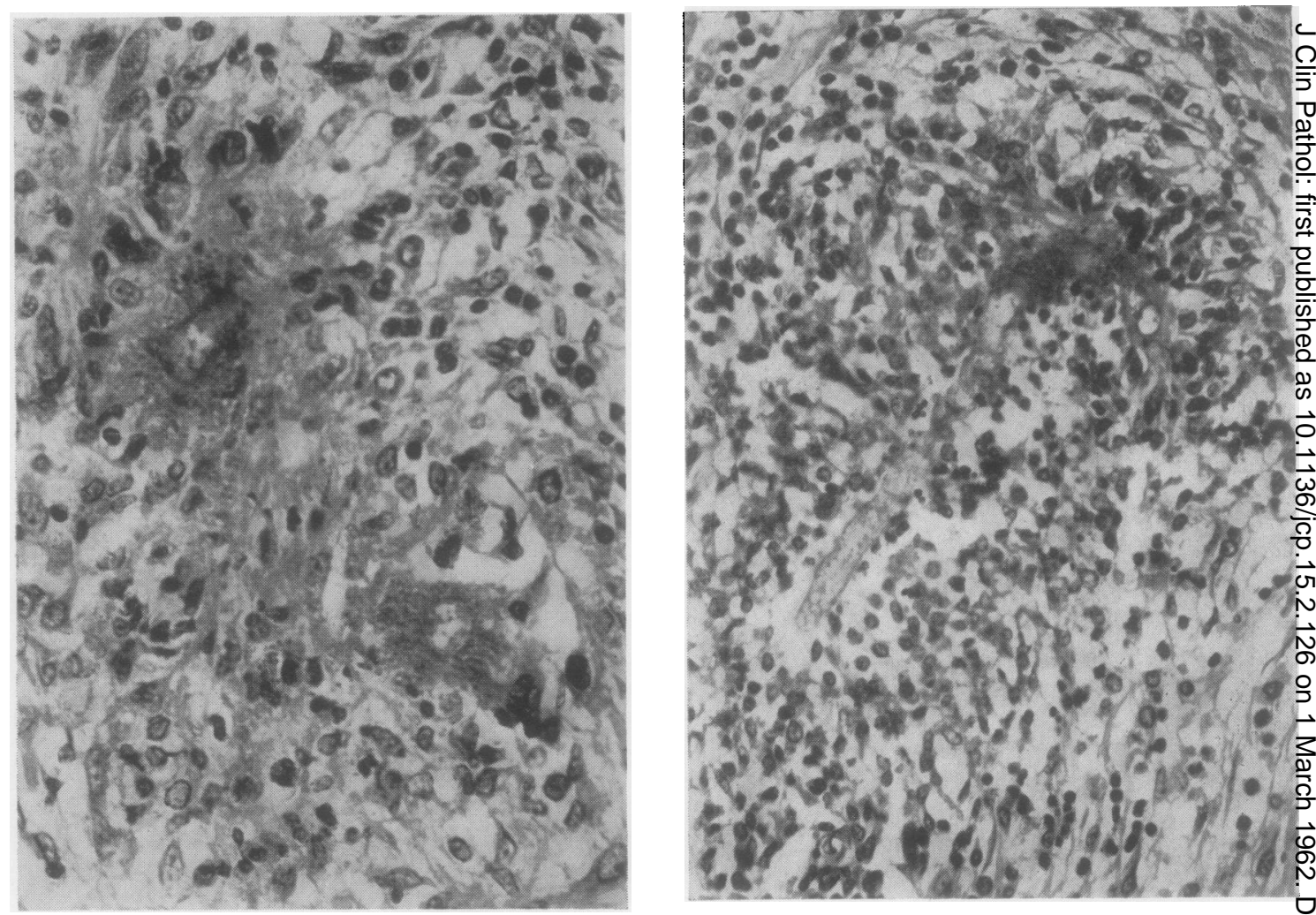

FIG. 3

FIG. 4

FIG. 3. Hyphae with surrounding granular eosinophilic substance (haematoxylin and eosin $\times 280$ ).

FIG. 4. Hypha in centre of an early microabscess. Note eosinophilic substance around part but not all of the hypha (hae.ळ matoxylin and eosin $\times 280$ ).

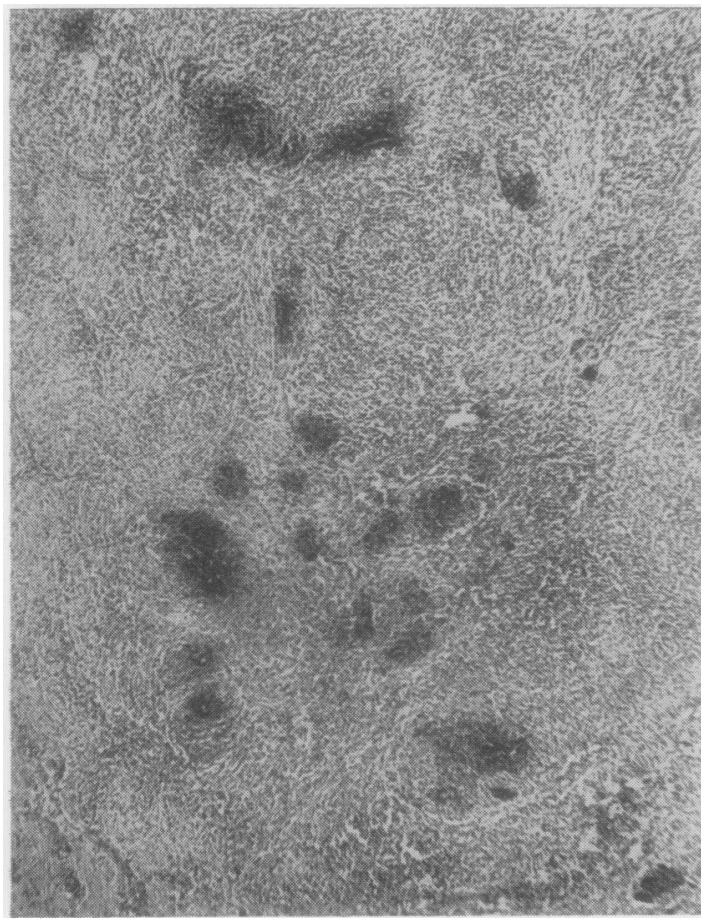

FIG. 5

FIG. 5. Granulomatous tissue with scattered microabscesses, some of which contain hyphae (haematoxylin and eosin $\times 280$ )? FIG. 6. Two hyphae with surrounding diffuse cellular infiltrate in muscle (haematoxylin and eosin $\times 280$ ). 


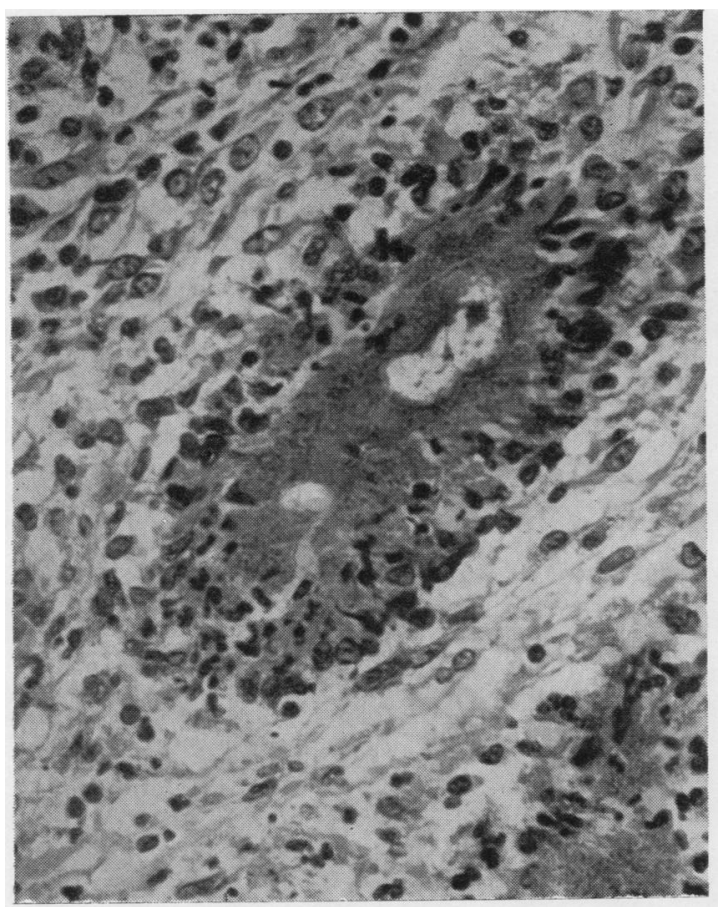

FIG. 7

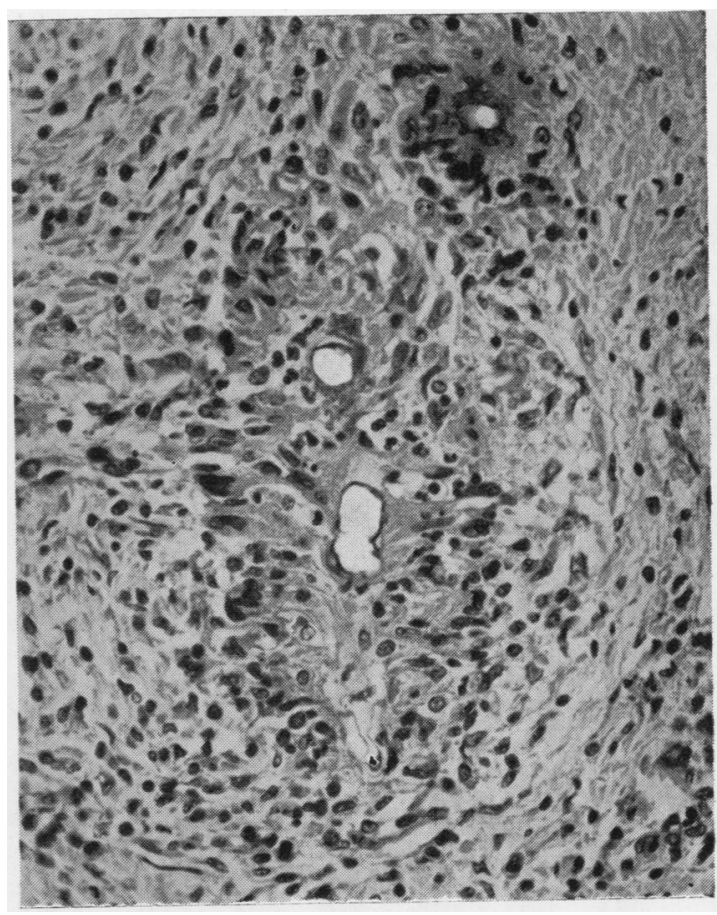

FIG. 8

FIG. 7. A well-developed microabscess with central hyphae and eosinophilic granular substance (haematoxylin and eosin $\times 280$ ).

FIG. 8. A well-developed microabscess with central empty hyphae and palisade of histiocytes (haematoxylin and $\operatorname{eosin} \times 280$ ).

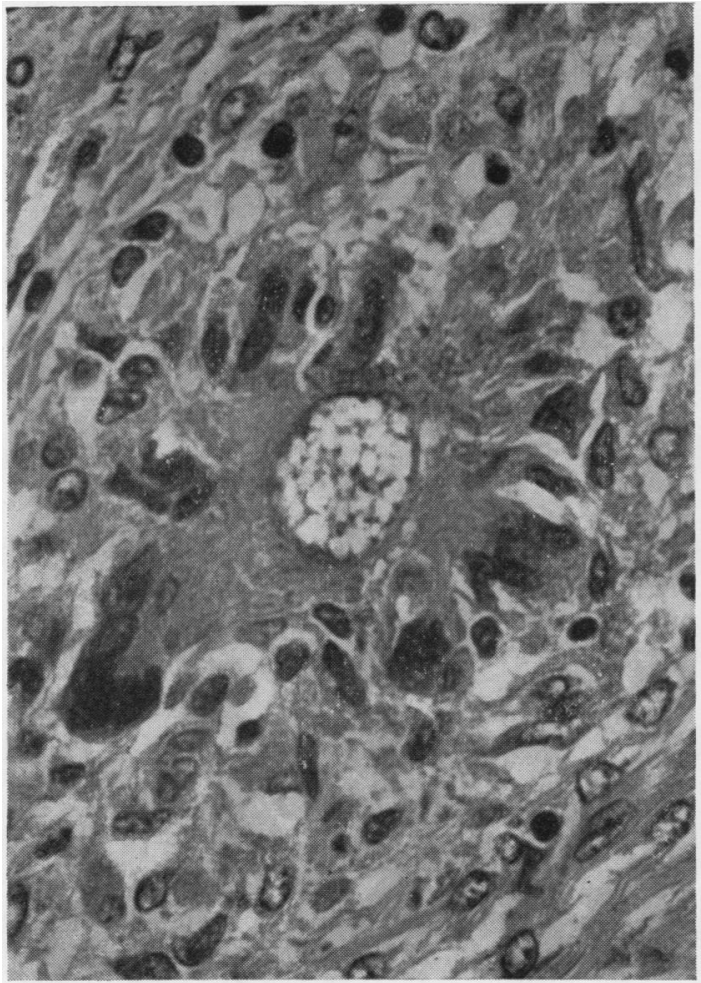

FIG. 9

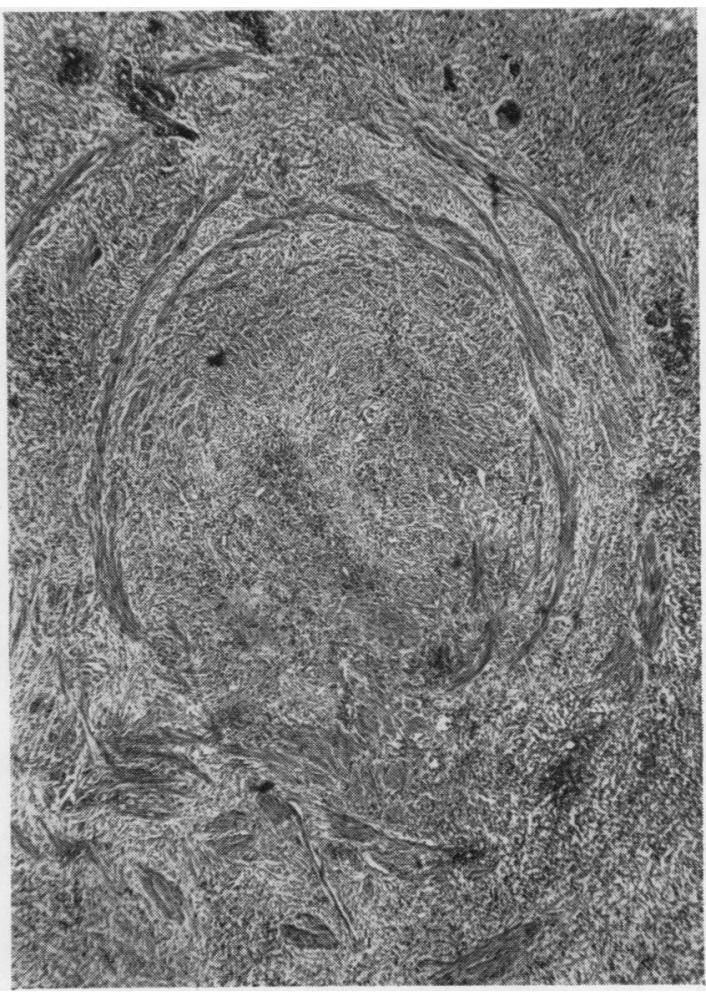

FIG. 10

FIG. 9. Fusion of histiocytes to form multinucleate giant cells around a hypha (P.A.S. and haematoxylin $\times 750)$. FIG. 10. A large blood vessel with hyphae infiltrating the outer muscle coat and a reactionary endarteritis occluding the lumen (haematoxylin and eosin $\times 50$ ). 
The granulomatous reaction consists of a rather densely fibrous connective tissue in which microabscesses, with or without central hyphae, are scattered (Fig. 5). Sometimes, as at the advancing edge of the granulomatous tissue where it invades the muscle, the hyphae are surrounded by a diffuse polymorphonuclear leucocyte infiltration (Fig. 6), and occasionally there is true tissue necrosis. The muscle fibres show a diffuse hyaline degeneration. In other areas the microabscesses show a peripheral ring or palisade of large histiocytes or macrophagetype cells around the hyphae and the eosinophilic substance (Figs. 7 and 8). There are groups of large multinucleated giant cells, often containing eosinophilic granular substance and fragments of hyphae (Fig. 9).

Eosinophils are a prominent feature both of the diffuse cellular infiltrate and of the microabscesses. A mononuclear cell infiltrate of plasma cells and lymphocytes and scattered lymphoid follicles containing germinal centres are also present in the fibrotic granulomatous tissue.

Most of the blood vessels show no lesion but occasionally there is a proliferative endarteritis which, in two or three large vessels, completely occludes the lumen. Two of these vessels show hyphae infiltrating the outer muscle coat with the characteristic focal inflammatory reaction around them and a fairly dense, diffuse cellular infiltrate throughout the walls and the connective tissue filling the obliterated lumen (Fig. 10). In the numerous sections examined there is no evidence of thrombosis either in the small or large vessels, nor is there any evidence of recanalization or haemosiderin deposition within the occluded vessels.

The infective process is situated mainly in the deeper subcutaneous tissues but it also involves the muscle (Fig. 6). The epidermis and immediately subjacent dermis, together with the skin appendages, show no significant changes other than a light focal mononuclear cell infiltrate.

\section{DISCUSSION}

The phycomycetes form an important class among the fungi which make up the moulds. They are common saprophytes on soil, dead and decaying vegetation, fruit, and starchy food. They are also frequent contaminants of routine laboratory cultures.

The commonest phycomycetosis is due to organisms of the family Mucoraceae (mucormycosis). These fungi have been isolated from the nose and gastrointestinal tract in normal people where they may be regarded as harmless contaminants but occasionally they have been identified in chronic pulmonary disease where they were probably saprophytic and secondary invaders. Sometimes they have been considered to produce a dermatitis or externalo otitis.

Deep-seated mucormycotic infections are often acute and they are usually fatal. They frequentlyo occur as a complication of leukaemia, carcinoma, multiple myeloma, widespread burns, cirrhosis, $\frac{\overline{ }}{\square}$ infantile diarrhoea, and treatment with antibiotics, $\stackrel{\mathbb{Q}}{\stackrel{\Omega}{\circ}}$ corticosteroid hormones, and A.C.T.H. (Zimmer-® mann, 1955; Long and Weiss, 1959). The particular systemic disease associated with mucormycosis is uncontrolled diabetes mellitus (Harris, 1955; Baker, $\vec{\omega}$ 1957), but although this clinical association is sup-o ported by certain experimental evidence by Elder and Baker (1956) and Baker, Schofield, Elder, and Spoto $G$ (1956), other authors do not agree (Zimmermann, î 1955; Keye and Magee, 1956).

Mucormycosis most commonly affects the braino (Harris, 1955; Long and Weiss, 1959) and lungs? (Baker, 1957). Other sites, e.g., the ocular region(Gass, 1961a and 1961b) and the alimentary tracts (Moore, Anderson, and Everett, 1949; Watson 1957; and Baker, Bassert, and Ferrington, 1957) are? less frequently involved. Subcutaneous mucor $\vec{\circ}$ mycosis has been described very infrequently. AN fungus of the family Mucoraceae was cultured in cases of paronychia occurring in orange peelers (Sutherland-Campbell, 1929; Sutherland-Campbelę and Plunkett, 1934) and in a patient in whom the lesion presented as two large papules of the face (Wade and Matthews, 1940). On histological grounds only Josefiak, Foushee, and Smith (1958) identifiec one of these organisms in a chronic leg ulcer.

Infections of man with phycomycetes of the families Entomophthoraceae and Mortierellaceae are very rare. However, a subcutaneous phycomycetosiș due to fungi other than the Mucoraceae has recently? been reported from Indonesia. In several papers Lie Kian Joe et al. (1956) and Lie Kian Joe and Eng? Njo-Injo Tjoei (1960) have described four cases of this disease and have mentioned a fifth. Symmers (1960) recorded a closely similar subcutaneous phycomycetosis ('mucormycotic granuloma' occurring in a Dutch girl in whom the infection o was considered to have been contracted in Indonesia. The diagnosis was based on the clinicas and histological features only as cultures were notw possible. Lie Kian Joe et al. have isolated a species? of Basidiobolus from three cases; in the first of these it was specifically identified as $B$. ranarun (Emmons, Lie Kian Joe, Eng, Njo-Injo Tjoei, Pohan; Kertopati, and van der Meulen, 1957). In a fourth case only limited culture studies were possible and attempts to induce sporulation failed. This organism was considered to be possibly a Mortierell $\mathbb{8}$ and not a species of Basidiobolus. The only othe report of a human infection with Basidiobolus is tha\$ 
of Casagrandi (1931) who identified this organism in a gastric ulcer but his findings are of doubtful significance. The genus Basidiobolus belongs to the family Entomophthoraceae and is a saprophytic fungus found in the gastrointestinal contents of several insectivores, e.g., frogs, toads, gekkoes, and lizards. The mode of infection of human beings is unknown.

The clinical features common to these subcutaneous phycomycetoses, other than the mucormycoses, as exemplified in the present case, are a painless slowly developing granulomatous infection of the deeper subcutaneous tissues, covered by intact skin, occurring in children from 4 to 13 years of age, not affecting the general health and usually healing spontaneously. No particular site is affected; the infection has occurred in the chest wall, upper arm, thigh, scrotum, and interscapular region. In contrast to mucormycosis there is no association with a particular systemic disease or drug administration. Several of the previously reported cases occurred in Indonesia but the present case, occurring in the Sudan, obviated any specific geographical factor peculiar to Indonesia, and our attention has been drawn to a further example of $B$. ranarum infection observed by Dr. Wilson of Makerere College, Kampala, Uganda.

The histological features of these subcutaneous phycomycetoses are fairly specific. In all cases the deeper subcutaneous tissues are involved, with the formation of a granuloma characterized by lesions in different stages of development around the hyphae.

Initially the hyphae stimulate a rather diffuse polymorphonuclear leucocyte reaction which later becomes more focal with the development of a microabscess. Eosinophils are a prominent feature of the cellular reaction. At the periphery of the microabscess histiocytes or macrophage-type cells accumulate, forming a characteristic margin or palisade effect. As the acute inflammatory cells disappear the histiocytes become more prominent and fuse to form multinucleated giant cells which ingest large fragments of hyphae and the surrounding eosinophil substance. Simultaneously with these tissue reactions a diffuse fibrosis occurs and many of the hyphae seem to collapse, fragment, and presumably die. It must be emphasized that this is an interpretation of the events and in any one section all phases of the process may be seen.

In the present case a histological feature not previously reported in these subcutaneous phycomycetoses is the invasion of the walls of large blood vessels by the fungal hyphae with a resultant reactionary endarteritis. A similar invasion of blood vessels with thrombosis and infarction is described as a characteristic feature of 'mucormycosis'.
Though thrombosis of small vessels is mentioned in the case reported by Symmers (1960), such an acute vascular reaction was not observed in the present case even though acute microabscesses were seen close to the vessel walls. The histological findings in mucormycosis and in subcutaneous phycomycetosis due to phycomycetes other than the Mucoraceae are in accord with the clinical pictures of the two conditions, acute and fatal in the former and chronic and self-healing in the latter.

The morphological features of the fungus in tissue sections, which are easily observed and permit a confident diagnosis of a phycomycetosis, are thinwalled hyphae of large diameter, $5 \mu$ to $25 \mu$, branching, and rarely septate. In the present case the hyphae were numerous, but in some cases their discovery may require the study of several sections. The granular eosinophilic substance around the hyphae may be of particular value in the diagnosis as this feature has not been described in mucormycotic infections of the subcutaneous or deeper tissues. Lie Kian Joe et al. (1960) interpret the eosinophilic substance around the hyphae as a 'peculiar tissue necrosis'. To explain the absence of this substance around certain hyphae they postulate that such hyphae are degenerating or dead. We do not favour this interpretation. Hyphae which appear to be active may not be surrounded with the eosinophilic substance, and, as illustrated, certain hyphae in the centre of microabscesses may show this granular substance only around part of their length. These findings and examination of the early formation of the substance (Fig. 2) suggest to us that this characteristic eosinophilic material is a product, probably degenerative, of the fungus. Its nature is not known but it does not seem to be fibrin from the limited studies reported here. Whether or not the nucleus observed in occasional hyphae in the present case will prove of any diagnostic value must await the investigation of further cases of this disease.

Unfortunately, though essential for accurate identification, culture of the organism is not always possible. It is believed, however, that the morphology of the fungus and the associated tissue reaction readily permit a diagnosis of phycomycetosis. Furthermore, the histological features described are considered to be sufficiently specific to separate the families of Entomophthoraceae and Mortierellaceae from the more common Mucoraceae. At present the histological picture described has been associated most commonly with Basidiobolus infections but further combined cultural and histological studies are needed to confirm or refute the possibility of separating the infections caused by members of the Entomophthoraceae and Mortierellaceae on a histological basis only. 
We are indebted to Mr. Beckwith for the photomicrographs and to Dr. J. Walker and Professor W. St. C. Symmers for their opinions on the sections which were referred to them.

\section{REFERENCES}

Baker, R. D. (1957). J. Amer. med. Ass., 163, 805.

Bassert, D. E., and Ferrington, E. (1957). A.M.A. Arch. Path., 63, 176.

_- Schofield, R. A., Elder, T. D., and Spoto, A. P. (1956). Fed. Proc., 15, 506.

Bauer, H., Ajello, L., Adams, E., and Useda Hernandez, D. (1955). Amer. J. Med., 18, 822.

Casagrandi, C. (1931). Riv. Biol., 13, 1

Elder, T. D., and Baker, R. D. (1956). A.M.A. Arch. Path., 61, 159

Emmons, C. W., Lie Kian Joe, Eng, Njo-Injo Tjoei, Pohan, A. Kertopati, S., and Meulen, A. van der (1957). Mycologia, 49, 1.

Gass, J. D. Mc. (1961a). Arch. Ophthal. (Chicago), 65, 214. (1961b). Ibid., 65, 226.

Gregory, J. E., Golden, A.. and Haymaker, W. (1943). Bull. Johns Hopk. Hosp., 73, 405
Harris, J. S. (1955). Pediatrics, 16, 857.

Hutter, R. V. P. (1959). Cancer (Philad.), 12, 330.

Josefiak, E. J., Foushee, J. H. S., and Smith, L. C. (1958). Amer. clin. Path., 30, 547.

Keye, J. D., and Magee, W. E. (1956). Ibid., 26, 1235

Lie Kian Joe, and Eng, Njo-Injo Tjoei (1960). Ann. N.Y. Acad. Sci. 89, 4.

Pohan, A., Meulen, H. van der, and Emmons, C. Wo (1956). A.M.A. Arch. Derm., 74, 378.

- - , Tjokronegoro, Sutomo, Schaafma, S., and Emmons, C尺 W. (1959). Amer. J. clin. Path., 32, 62. $-1, \frac{1}{\text { Hyg., 9, } 143 .}$, and Emmons, C. W. (1960). Amer. J. trop. Med?

Long, E. L., and Weiss, D. L. (1959). Amer. J. Med., 26, 625.

Moore, M., Anderson, W. A. D., and Everett, H. H. (1949). Amer. $J$ Path., 25, 559.

Sutherland-Campbell, H. (1929). Arch. Derm. Syph. (Chicago), 19, 233.

—, and Plunkett, O. A. (1934). Ibid., 30, 651.

Symmers, W. St. C. (1960). Brit. med. J., 1, 1331. Symmers, W. St. C. (1960). Brit. med. J., 1, 1331 .
Wade, J. L., and Matthews, A. R. K. (1940). J. Amer. med. Ass., 114 $\overrightarrow{\mathrm{G}}$
410.

Watson, K. C. (1957). S. Afr. med., J., 31, 99.

Zimmermann, L. E. (1955). Amer. J. clin. Path., 25, 46. 